\title{
Charcoal on Wall
}

Christina C. Dy
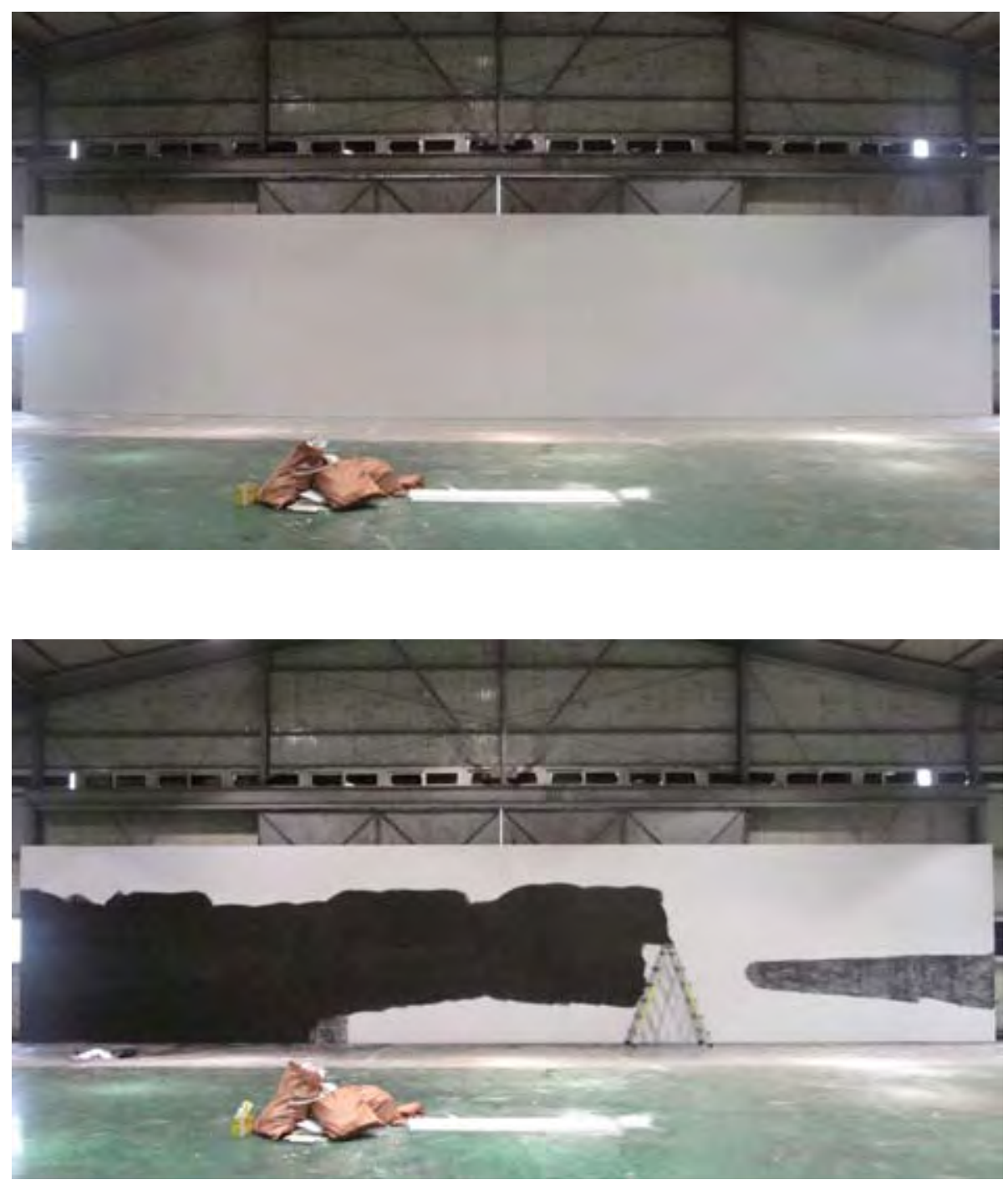

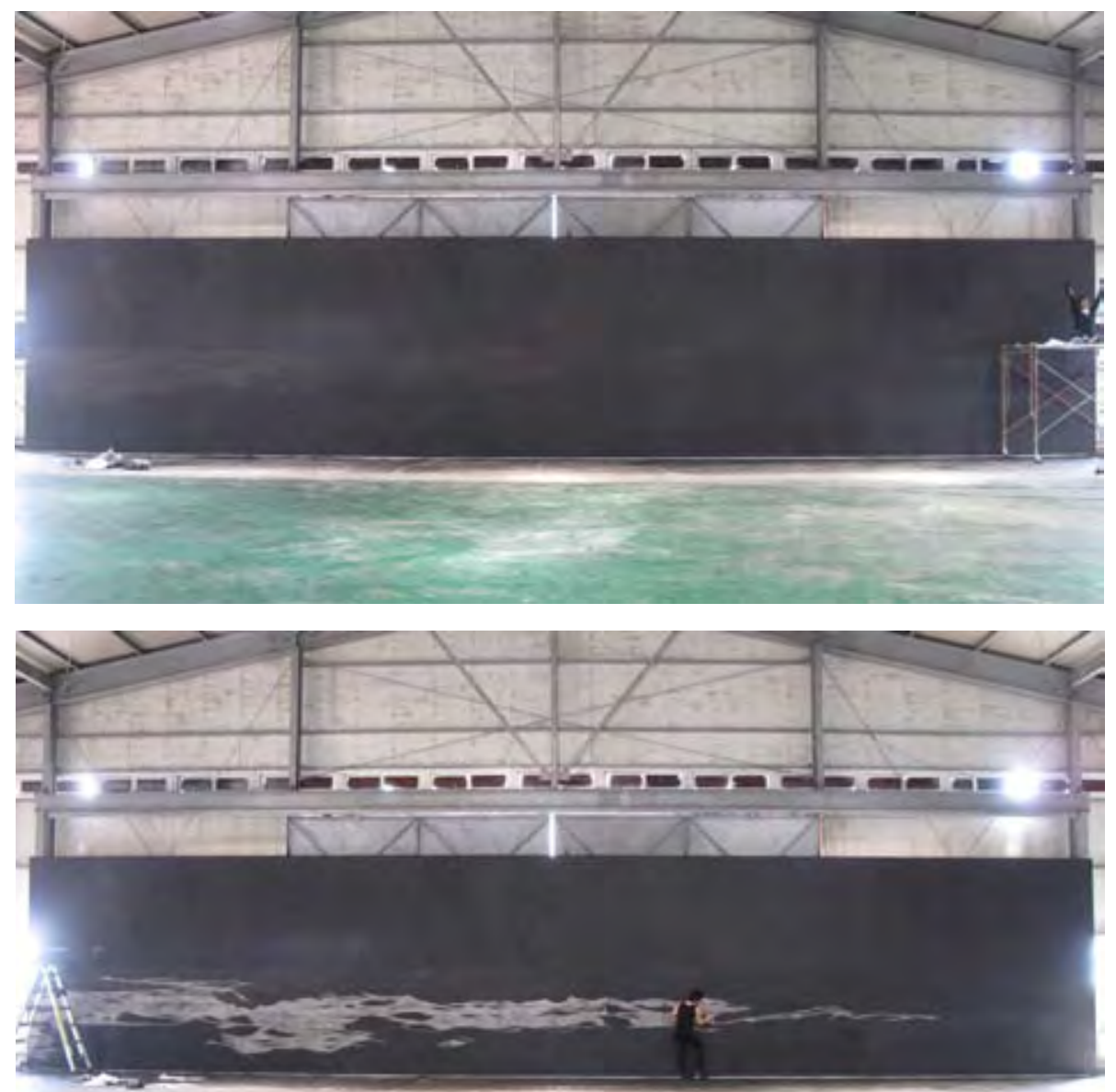

The seas and oceans are timeless. They have been there long before we existed; they will be there when all of us are gone. The waters of the earth have been witness to human history. They are also ever-changing; and sadly, bear the effects of human error. 

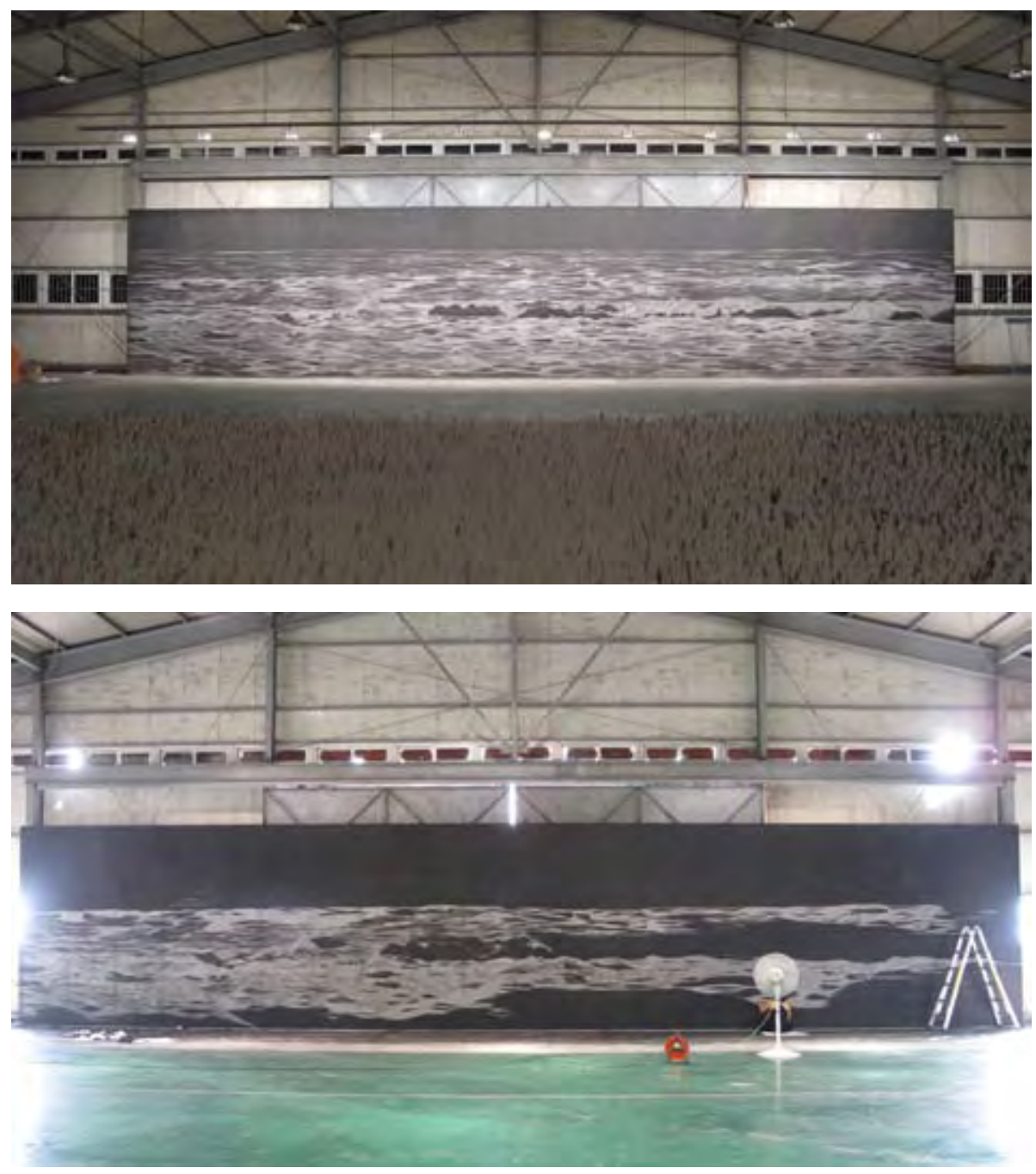

I have chosen to draw the earth's waters for this biennale. It will be drawn with charcoal, on the wall, large-scale, trying to capture its vast organic quality. 

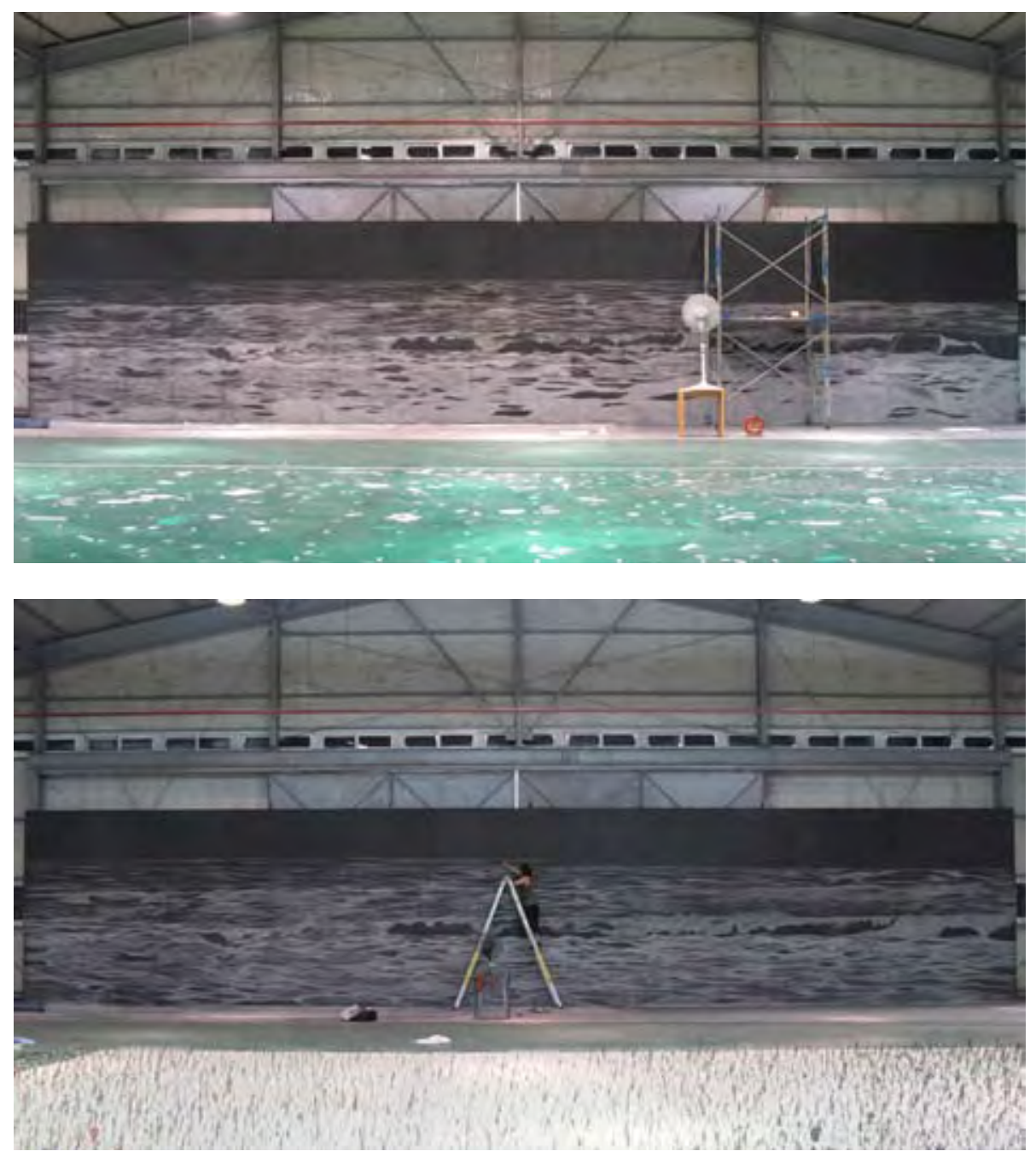

I have always been interested in capturing moments-something from as small as a crease in a shirt after lovemaking, to something as big as a wave right before it crashes onto the shore. As such, my work will not be preserved after this biennale. Everything is temporary, even the seas and oceans. Everything that has a beginning has an end. 